\title{
Social interactions change with season and age in Northern Bald lbis
}

\author{
Verena Puehringer-Sturmayr ${ }^{1,2}\left([) \cdot\right.$ Tanja Stiefel $^{1} \cdot$ Kurt Kotrschal $^{1,2} \cdot$ Sonia Kleindorfer ${ }^{1,2,3} \cdot$ Didone Frigerio $^{1,2}$
}

Received: 14 January 2020 / Revised: 2 September 2020 / Accepted: 23 September 2020 / Published online: 8 October 2020

(c) The Author(s) 2020

\begin{abstract}
Understanding the association between an individual's position within a social network and its sex and age across seasons can be useful information for conservation management. For example, identifying the social position of females within a group can provide insights into reproductive potential, while the position of juveniles may be related to survival and hence recruitment potential. In the present study, we used social network analysis to investigate the effects of season, sex, age and reproductive partner on social interactions in the endangered Northern Bald Ibis (Geronticus eremita). Via focal sampling we recorded the social behaviour of 39 individually marked, free-flying birds for 4 months over two seasons (autumn, winter). We observed the occurrence of affiliative and agonistic interactions and estimated proximity between colony members. We found that (1) individuals were in proximity with more colony members in winter than in autumn, and affiliative interactions occurred more often in winter, (2) older individuals occupied more central positions in the proximity network irrespective of sex, (3) males engaged more than females in agonistic interactions, whereas females received more affiliative interactions than males irrespective of age, and (4) most affiliative interactions occurred between former or potentially prospective reproductive partners. Our findings suggest that social relationships could modulate inter-individual distance and there may be sex-related differences in the investment into pair bond maintenance. Overall the findings of sex- and age-related differences in behaviour and social position contribute to understanding factors associated with breeding success and mortality risk in an endangered bird species.
\end{abstract}

Keywords Affiliative interactions · Agonistic interactions $\cdot$ Juvenile recruitment $\cdot$ Colonial $\cdot$ Geronticus eremita . Proximity $\cdot$ Social network $\cdot$ Conservation $\cdot$ Endangered species

Communicated by S. Bouwhuis.

Verena Puehringer-Sturmayr and Tanja Stiefel share first authorship.

Verena Puehringer-Sturmayr and Tanja Stiefel contributed equally to the manuscript.

Electronic supplementary material The online version of this article (https://doi.org/10.1007/s10336-020-01824-2) contains supplementary material, which is available to authorized users.

Verena Puehringer-Sturmayr

verena.puehringer-sturmayr@univie.ac.at

Tanja Stiefel

tanjastiefel@gmx.at

Kurt Kotrschal

kurt.kotrschal@univie.ac.at

Sonia Kleindorfer

sonia.kleindorfer@flinders.edu.au

Didone Frigerio

didone.frigerio@univie.ac.at
1 Core Facility Konrad Lorenz Research Center for Behaviour and Cognition, University of Vienna, Fischerau 11, 4645 Grünau im Almtal, Austria

2 Department of Behavioural and Cognitive Biology, University of Vienna, Althanstrasse 14, 1090 Vienna, Austria

3 College of Science and Engineering, Flinders University, Adelaide 5001, Australia 


\section{Zusammenfassung}

\section{Soziale Interaktionen beim Waldrapp ändern sich mit der Jahreszeit und dem Alter.}

Das Verständnis des Zusammenhangs zwischen der Position eines Individuums innerhalb eines sozialen Netzwerks über die Jahreszeiten hinweg und dessen Geschlecht und Alter können eine nützliche Information für die Planung von Naturschutzmaßnahmen sein. Beispielsweise kann die Ermittlung der sozialen Position von Weibchen innerhalb einer Gruppe Einblicke in das Reproduktionspotential geben, während die Position von Jungtieren mit dem Überleben und somit dem Rekrutierungspotential zusammenhängen kann. In der vorliegenden Studie untersuchten wir mit Hilfe der sozialen Netzwerkanalyse die Auswirkungen von Jahreszeit, Geschlecht, Alter und Paarpartner auf die sozialen Interaktionen beim stark gefährdeten Waldrapp (Geronticus eremita). Mittels Beobachtungen von Fokustieren erfassten wir das Sozialverhalten von 39 individuell markierten, frei fliegenden Vögeln über vier Monate zu zwei Jahreszeiten (Herbst, Winter). Wir beobachteten das Auftreten von sozio-positiven und sozio-negativen Interaktionen und untersuchten die Nähe zwischen den Mitgliedern der Kolonie. Wir stellten fest, dass (1) die Individuen im Winter in der Nähe von mehr Koloniemitgliedern waren als im Herbst und dass sozio-positive Interaktionen im Winter häufiger auftraten, (2) ältere Individuen unabhängig vom Geschlecht zentralere Positionen im Netzwerk bezogen auf die räumliche Nähe der Tiere zueinander einnahmen, (3) die Männchen an mehr sozio-negativen Interaktionen beteiligt waren als die Weibchen, während die Weibchen unabhängig vom Alter mehr sozio-positive Interaktionen erhielten als die Männchen, und (4) die meisten sozio-positiven Interaktionen zwischen ehemaligen oder potentiellen Paarpartnern auftraten. Unsere Ergebnisse deuten darauf hin, dass soziale Beziehungen die Distanz zwischen den Individuen modulieren könnten und dass es möglicherweise geschlechtsbezogene Unterschiede bei der Investition in die Aufrechterhaltung von Paarbindungen gibt. Insgesamt tragen die Erkenntnisse über geschlechtsund altersbedingte Unterschiede im Verhalten und in der sozialen Stellung zum Verständnis der Faktoren bei, die mit dem Bruterfolg und dem Sterblichkeitsrisiko bei einer gefährdeten Vogelart zusammenhängen.

\section{Introduction}

Sociality influences survival and reproductive success (Davies et al. 2012) via modulating the costs and benefits associated with predation risk, access to food (Krause and Ruxton 2002), and information (Dall et al. 2005). Tradeoffs between foraging behaviour and antipredator behaviour are well-documented (Verdolin 2006), and the strength of association has been shown to be modulated by social factors (e.g., group size, group composition), individual factors (e.g., age, sex), and environment (e.g., habitat structure, season; Widdig et al. 2001; Lehmann et al. 2007; Boucherie et al. 2016; Strandburg-Peshkin et al. 2017). Affiliative interactions, for instance, can be used to quantify social relationships in complex social systems (Wey et al. 2008). Intense social relationships are observed between reproductive partners as well as parents and offspring (Dunbar and Shultz 2010), but also between unrelated group members (Silk et al. 2006; Lehmann et al. 2007; Cameron et al. 2009; Palagi and Cordoni 2009; Boucherie et al. 2016).

Understanding behavioural variation associated with sex and age in relation to group-level attributes is particularly important for conservation management (Bengston and Jandt 2014; Estrada et al. 2017). Reproductive success may be influenced by the quality of long-term social bonds (Silk 2007) as well as by an individual's social position within a group. Highly social female White-Faced Capuchin Monkeys (Cebus capucinus imitator) with many affiliative ties, for example, occupy a central social position and have increased offspring survival as compared to other females in the same group (Kalbitzer et al. 2017). Mortality risk may also be associated with an individual's social position within a group (Kurvers et al. 2014). Yellow-Bellied Marmots (Marmota flaviventris) with few affiliative ties, for instance, tend to experience high mortality risk (Blumstein et al. 2009). In contrast, agonistic networks can generate information about the competitive abilities of individuals. Older adult Yellow-Bellied Marmots seem to initiate more and receive fewer agonistic interactions than younger adults (Wey and Blumstein 2010). This may increase male reproductive success, because females tend to prefer competitive males (Hirsch and Maldonado 2011). Affiliative interactions are shaped by socio-positive relationships (Hirsch et al. 2012), while inter-individual distance (i.e., proximity) within a group is shaped by agonistic interactions and food competition (Hirsch et al. 2012) as well as predator avoidance (Romey and Wallace 2007). Social relationships within groups can be quantified by network analysis, which is a useful tool to quantify sex and age patterns of affiliative and agonistic interactions and proximity in group living animals. Such knowledge can be applied to better understand individual variation in species of conservation concern (Jacoby et al. 2011; Snijders et al. 2017).

An individual's decision about 'with whom' and 'to which extent' to interact in a group can be affected by intrinsic (e.g., motivation, sex, age) and extrinsic (e.g., proximity, group composition) factors that may vary across seasons (Whirligig Beetles (Coleoptera, Gyrinidae): Romey and Wallace 2007; Yellow-Bellied Marmots: Wey and Blumstein 2010; White-Faced Capuchins: Crofoot et al. 2011). 
For instance, in complex social systems, where individuals tend to associate with friends of their friends, such long-term social relationships are known to modulate the number of affiliative ties among members of a group (Vervet Monkeys (Chlorocebus pygerythrus): Borgeaud et al. 2016; Spotted Hyenas (Crocuta Crocuta): Illany et al. 2015). Relationship patterns may dynamically change across time as individuals join or leave a group (Blonder et al. 2012; Kubitza et al. 2015 ) in the course of seasonal migratory and dispersal processes (Idani 1991; Blumstein et al. 2009; Pinter-Wollman et al. 2009) as well as reproductive phases (Hamede, Bashford et al. 2009; Brent et al. 2013).

Understanding the social network of threatened groupliving animals is a core challenge for behavioural ecologists especially when the group composition is seasonal. In this study, we explore patterns of social behaviour and inter-individual distance (i.e., proximity) in the Northern Bald Ibis (Geronticus eremita), an endangered (BirdLife International 2020) colonial breeding species with fission-fusion foraging patterns. In addition to changes in seasonal movement, such as dispersal and/or local migration, and the formation of seasonally monogamous reproductive pairs, diurnal patterns of association form as the group roosts together at night and forages in subgroups during the day (Böhm and Pegoraro 2011). Individuals tend to form new reproductive pairs each year, though in some cases, partners of the previous year re-pair (Wickler and Seibt 1985; Böhm and Pegoraro 2011). The species is colonial throughout the year (del Hojo et al. 1992). Eggs are generally laid between March and May (del Hojo et al. 1992). Juveniles are cared for by the parents until approximately 2 weeks after fledging (Böhm and Pegoraro 2011). A social dominance hierarchy is generally established between the members of a colony, in which dominance rank increases with age (Sorato and Kotrschal 2006) and males are dominant over females (Böhm and Pegoraro 2011). Younger birds are more likely to disperse than older birds (Böhm et al. in press). Juveniles seem to have a different overwintering area than adults, which was observed in the extinct Middle East population (Lindsell et al. 2009). In this seasonally and socially dynamic system, understanding how age, sex and reproductive partners affect patterns of relationship between individuals can contribute to our knowledge of the potential link between sociality and fitness. Northern Bald Ibis affiliative interactions between pair partners scaled negatively with endoparasite burden during periods of elevated stress (e.g., reproductive period, PuehringerSturmayr et al. 2018) suggesting that being embedded in a pair bond may have a positive impact on individual fitness (Frigerio et al. 2016). Therefore, Northern Bald Ibis might be a suitable model to investigate the relationships between an individual's network position (including other metrics, such as density) and risks (e.g., disease transmission, increased competition) and opportunities (e.g., access to social information) with respect to reproduction and survival.

In the present study, we assessed the effect of season (autumn and winter), sex, age and reproductive partner on proximity between individuals and social behaviour (i.e., affiliative and agonistic interactions between colony members) in a free-flying and individually marked colony of Northern Bald Ibis. We tested the following predictions: (1) there will be an effect of season on inter-bird proximity and the number of agonistic and affiliative interactions, as Northern Bald Ibis engage in pre-breeding displays during autumn and establish new pair bonds during winter (Böhm and Pegoraro 2011), (2) there will be an effect of sex, age and reproductive partner on the observed patterns. Specifically, we predict (1) more agonistic interactions in males during winter than in autumn in competition for mates and nest sites, (2) therefore, generally more agonistic interactions in males than females, and (3) comparable levels of affiliative behaviours in males and females due to relatively symmetrical patterns of interaction within pairs (Sorato and Kotrschal 2006). We also predict that older and more experienced birds will occupy more socially central positions (determined through both affiliative and agonistic interactions in separate social networks) within the group during both seasons associated with known benefits of socially central positions for survivorship in males and females (Stanton and Mann 2012; Archie et al. 2014; Kalbitzer et al. 2017). Older and experienced birds may profit from a socially central position by reducing stress load via affiliative ties (Puehringer-Sturmayr et al. 2018), by increasing fitness via the engagement in breeding activities (Formica et al. 2012; Kalbitzer et al. 2017), and by gaining access to resources via agonistic encounters and rank acquisition (Kulahci et al. 2016).

\section{Methods}

\section{Study population and area}

A colony of free-flying Northern Bald Ibis was established at the Konrad Lorenz Research Center (KLF) in 1997 in coordination with the European Breeding Programme (Böhm 1999; Tuckova et al. 1998). This research facility is situated $5 \mathrm{~km}$ south of Grünau im Almtal/ Upper Austria $\left(47.852778^{\circ} \mathrm{N}, 13.955556^{\circ} \mathrm{E}\right)$. The birds are housed in a year-round open aviary (approximately $20 \times 15 \times 7 \mathrm{~m}[\mathrm{~L} \times \mathrm{B} \times \mathrm{H}]$; referred to as 'nesting site' hereafter) in the local Cumberland Game Park. The aviary is used for roosting as well as for breeding in spring. The birds can leave the aviary at any time and roam the foraging grounds in the area. During winter (from midDecember until March) and depending on the harsh alpine 
weather conditions, the ibis generally stay at their nesting site. The birds are supplemented with food twice per day during winter periods when resources are scarce and later during spring at the continuation of the breeding season (hash made from 1-day-old chicks and beef heart, mixed with insects and water-soaked dog food; generally from November to May). All the birds are individually marked with coloured leg rings. Birds were habituated to the presence of humans. Observations were conducted in the surroundings of the Konrad Lorenz Research Center (i.e., meadows and a river with gravel banks) and the adjacent Cumberland Game Park (i.e., at their nesting site). At the start of data collection, the colony consisted of 39 individuals (24 males and 15 females, aged from 7 months to 17 years; mean age $\pm \mathrm{SD}=3.92 \pm 4.52$; Table $\mathrm{S} 1$ ).

\section{Data collection}

Data were collected from 21 October 2016 until 28 February 2017. The observation period was divided into two phases: (1) autumn, data collected from October to December and (2) winter, data collected from January to February. Observations were performed between 0800 $\mathrm{AM}$ and $0400 \mathrm{PM}$ of all birds present at that time. We did focal observations of all birds by applying a continuous recording method (Altmann 1974) with each protocol lasting $10 \mathrm{~min}$. Each individual was observed $46.5 \pm 1.7$ times (mean $\pm \mathrm{SE}$ ), totalling 1814 observation protocols. TS collected a total number of 890 protocols during autumn $\left(\mathrm{N}_{\text {protocols field }}=727, \mathrm{~N}_{\text {protocols aviary }}=163\right)$ and a total number of 924 protocols during winter $\left(\mathrm{N}_{\text {protocols field }}=211\right.$, $\mathrm{N}_{\text {protocols aviary }}=713$ ). All behavioural data were collected with the software Prim8 Mobile (mobile computing to record nature, https://www.prim8software.com/; McDonald and Johnson 2014). We monitored frequencies of initiated and received affiliative (greeting, bill shaking, clasped necks, preening invitation, preening, contact sitting) and agonistic behaviours (threat, threat greeting, pecking, defensive threat, displacement, attempted displacement, fighting; for a detailed description of the listed behaviours see Pegoraro 1992). Additionally, proximity ( $<0.5 \mathrm{~m}$, based on previous observations; measured as duration) of the focal animal to other colony members was measured by visual estimation. For each colony member that came within a $0.5 \mathrm{~m}$ radius of the focal individual during the $10 \mathrm{~min}$ observation time, we recorded the duration of the proximity between the focal bird and other colony members. Proximity estimation for ibis was trained before starting data collection by estimating and then measuring the distance between bins.

\section{Data analysis}

Social network analyses and calculation of network metrics were performed in Ucinet v. 6.699 (Bogatti et al. 2002). The randomization procedures to determine if the networks are 'non-random' were computed in $\mathrm{R}$ version 4.0.2 ( $\mathrm{R}$ Core Team 2020). For the visualisation of the networks, we used the software Gephi 0.9.2 (Bastian et al. 2009). To analyse the influence of age on the position of the individuals within the network, the age in months was calculated for each focal animal. Since preliminary analysis showed differences in the network metrics (i.e., degree, in-degree, out-degree, eigenvector centrality) of proximity and affiliative interactions between autumn and winter (Wilcoxon signed rank test with continuity correction conducted via $\mathrm{R}$ version 3.6.1 (R Core Team 2019); see results), we analysed the two seasons for all response variables in separate models.

Proximity (i.e., all colony members within $0.5 \mathrm{~m}$ of the focal individual) was measured to analyse the inter-individual distance during natural foraging and roosting. Four directed and two undirected social networks were created (Farine and Whitehead 2015) for affiliative and agonistic interactions (one directed network each for autumn and winter) as well as proximity (one undirected network each for autumn and winter) split by season. Nodes were defined as the individuals within the colony and edges represented the interactions between those individuals. For affiliative and agonistic networks, edges represented the raw frequency count of interactions between individuals. In the proximity network, a simple ratio index (time observed together/time both observed $* 100$ ) was used to calculate the edge weights. Social networks were examined at node-, dyadic- and network-level. To measure individual variation in sociality at the node-level, we calculated different network metrics for each individual in each network representing initiated and received social interactions, i.e., weighted degree (sum of all individuals that interacted with a specific individual), weighted in-degree (corresponds to received affiliative and agonistic behaviours; number of colony members from whom an interaction is received), weighted out-degree (corresponds to initiated affiliative and agonistic behaviours; number of colony members towards which an interaction is initiated) and eigenvector centrality (a measure of social centrality within the network which is proportional to the sum of the centralities of an individual's neighbours). Those network metrics were selected, because we distinguished between initiated and received behaviours, and because in Northern Bald Ibis, affiliative interactions increase during the pre-breeding and breeding season and decrease after the offspring fledged; also, most affiliative interactions occur between former and prospective mates. Degree and eigenvector centrality measure the number of incident links and the quality of those links (i.e., the importance of nodes in a 
network), which is an important measure to assess how an individual's associations differ between sex of the interactants and change with season and age.

Binary networks (connection between two individuals was coded as 1 and no connection between two individuals was coded as 0 ) were used to calculate density at the network-level (proportion of possible connections used within a network).

To assess whether associations among pairs of individuals deviated from random variation, we performed prenetwork randomizations using data stream permutations for focal sampling data collection protocols and compared the strength of associations of the original and permuted data sets via t-test with the Animal Network Toolkit Software (ANTs) R package (Sosa et al. 2020). Data stream permutations swap a single association in each permutation and this permutation can be controlled according to the focal observation number.

Due to the non-independence of network data and consequently the violation of the assumptions of classical statistical analyses, we applied a random permutation approach. Using Node-Level Regression with 1000 permutations, we investigated which factors influenced social structure in the Northern Bald Ibis. Node-Level Regression performs a basic Ordinary Least Squares (OLS) linear regression and uses random permutations method for constructing sampling distributions of R-squared and slope coefficients to estimate standard errors and significance (Hanneman and Riddle 2005). We defined (1) degree (i.e., proximity), (2) out-degree (i.e., initiated affiliative and agonistic behaviours), (3) in-degree (i.e., received affiliative and agonistic behaviours) and (4) eigenvector centrality (i.e., proximity, initiated and received affiliative and agonistic behaviours) as dependent variables. Sex and age (in months) were included as independent variables.

At the dyadic-level a Double Dekker Semi-Partialling Multiple Regression Quadratic Assignment Procedure (MRQAP; Dekker et al. 2007) with 1000 permutations was used to examine whether same sex, differences in age and reproductive partners predict proximity and social interactions (affiliative and agonistic interactions) between individuals. MR-QAP performs a regression between a dependent matrix (i.e., observed data) and one or more independent matrices (e.g., similarities in attributes of nodes such as sex). The double semi-partialling algorithm proceeds in two steps: (1) a standard multiple regression is computed across corresponding cells of the dependent and independent matrices and (2) together rows and columns of the matrices are randomly permuted, after which the regression is recomputed. To estimate standard errors, this step is repeated 1000 times. For each coefficient, the proportion of random permutations that showed a coefficient as extreme as the one for observed values is counted. We conducted six separate MR-QAPs with the network proximity in autumn, proximity in winter, agonistic interactions in autumn, agonistic interactions in winter, affiliative interactions in autumn and affiliative interactions in winter as the dependent matrices, while sex-based homophily (same sex), age-based heterophily (differences in age in months) and reproductive partners (i.e., previous ones before 2017 and partners in 2017) were used as the independent matrices. For the homophily matrix, same sex dyads were coded as 1 , while different sex dyads were coded as 0 . In the heterophily matrix, the absolute difference of age in months between dyads was calculated. Former or prospective reproductive partners were coded as 1 and other conspecifics as 0 .

Results are presented as mean + standard deviation.

\section{Results}

\section{Proximity patterns}

The proximity network strength of association deviated from random variation during autumn $\left(\mathrm{t}_{\text {observed }}=32.687\right.$, $\mathrm{t}_{\text {permutation mean }}=36.389$, $\mathrm{p}_{\text {one-tailed }}=0.032$ ) and winter $\left(\mathrm{t}_{\text {observed }}=29.470, \mathrm{t}_{\text {permutation mean }}=35.765\right.$, $\left.\mathrm{p}_{\text {one-tailed }}=<0.001\right)$. We found an effect of season, reproductive partner and age on proximity patterns, but no differences in sex. In autumn, individuals spent less time in close proximity (i.e., $<0.5 \mathrm{~m}$ ) to conspecifics than in winter. The social centrality position of individuals within the colony did not differ between seasons (Table S2).

\section{Autumn}

Network density was high (97.3\%), meaning that almost all individuals within the colony were generally in close proximity to each other. Individuals spent more time in close proximity to previous or new reproductive partners compared to other colony members. Sex-based homophily or age-based heterophily did not influence proximity patterns within the colony (Table S3). No sex differences were found in proximity patterns and centrality position (Fig. 1a; weighted degree males $=34.88+13.29$, weighted degree females $=32.47+12.83$, eigenvector centrality males $=0.15+0.07$, eigenvector centralty $_{\text {females }}=0.14+0.07$ ). However, older individuals spent generally more time in close proximity to other colony members and thus occupied a more central position within the network than younger individuals (Table S4).

\section{Winter}

Network density decreased during winter (84.4\%) as compared to autumn, meaning that all individuals were generally 
Fig. 1 Undirected proximity networks of the Northern Bald Ibis colony during autumn (a) and winter (b). Males are highlighted in black, females in grey. Node size increases with the age of the individuals. Edge size represents how often an individual was observed near another colony member. $\mathrm{N}_{\text {males }}=24, \mathrm{~N}_{\text {females }}=15$
A

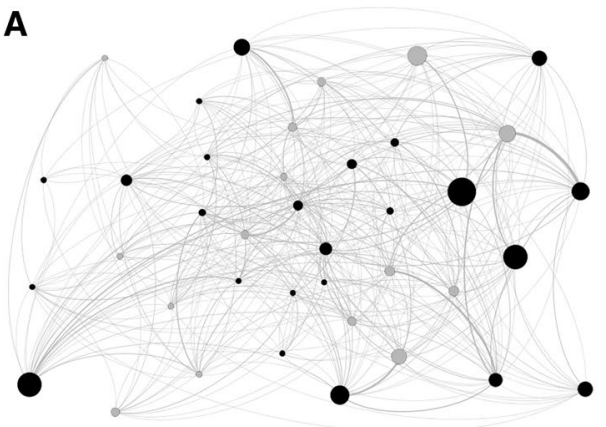

B

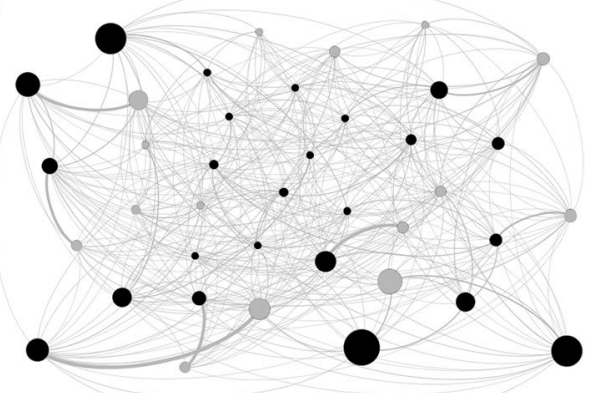

less often in close proximity to each other compared to autumn. Colony members spent more time in close proximity to previous or new reproductive partners compared to other individuals. Sex-based homophily and age-based heterophily had no effect on proximity patterns (Table S3). Sex did not influence proximity patterns and centrality position within the network (Fig. 1a; weighted degree ${ }_{\text {males }}=63.92+15.08$, weighted degree females $=56.00+18.97$, eigenvector centrality males $=0.15+0.06$, eigenvector centrality $_{\text {females }}=0.14+0.08$ ). Older birds spent more time in close proximity to other colony members and occupied more central positions (Table S4).

\section{Agonistic interactions}

The agonistic association network deviated from random variation during autumn $\left(\mathrm{t}_{\text {observed }}=9.245\right.$, $\left.\mathrm{t}_{\text {permutation mean }}=24.900, \mathrm{p}_{\text {one-tailed }}=0.006\right)$ and winter $\left(\mathrm{t}_{\text {observed }}=9.655, \mathrm{t}_{\text {permutation mean }}=23.384\right.$, $\left.\mathrm{p}_{\text {one-tailed }}=<0.001\right)$. We found no effect of season or reproductive partner, but effects of age and sex on patterns of agonistic interactions. Initiated and received agonistic interactions as well as the centrality position within the network did not differ between autumn and winter (Table S2).

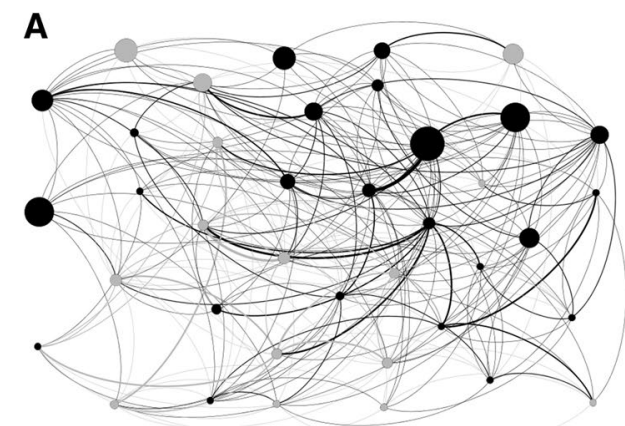

Fig. 2 Directed social networks of the initiated and received agonistic interactions in autumn (a) and winter (b). Males are highlighted in black, females in grey. Node size increases with the age of the individuals. Edge size represents how often an individual was involved

\section{Autumn}

A network density of $18.4 \%$ indicated low numbers of possible connections within the agonistic network during autumn. Agonistic behaviours were not shown towards previous or new reproductive partners. Sex-based homophily had no influence on the selection of interaction partner (Table S3) and sex did not modify initiating or receiving agonistic interactions (Fig. 2a; out-degree $_{\text {males }}=10.63+8.57$, out-

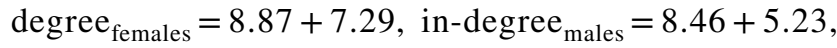
in-degree females $=12.33+4.56$ ). The centrality positions occupied within the social network did not vary with sex or age (Table S4; eigenvector centrality $y_{\text {males }}=0.14+0.06$, eigenvector centrality $\left._{\text {females }}=0.16+0.08\right)$. Agonistic interactions occurred mostly between individuals of similar age (Table S3). Younger individuals received more and initiated fewer agonistic interactions (Table S4).

\section{Winter}

As in autumn, the network density of the agonistic network during winter was $18.4 \%$, indicating only few connections between conspecifics. Previous or new reproductive partners were not engaged in agonistic interactions with

B

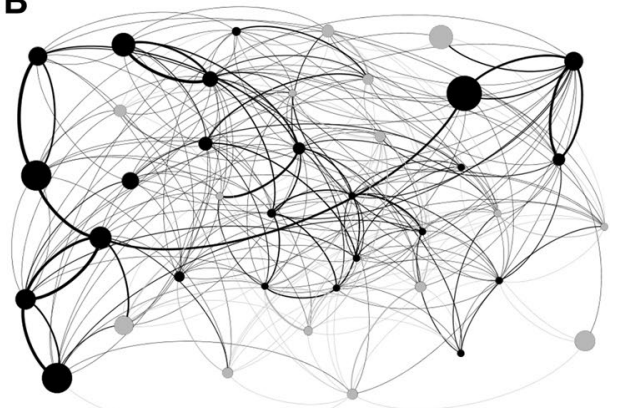

in an agonistic interaction with another colony member. Edge colour indicates the origin of the behaviour and the direction of the association is shown clockwise. $\mathrm{N}_{\text {males }}=24, \mathrm{~N}_{\text {females }}=15$ 
each other. Agonistic interactions were mostly exchanged between individuals of the same sex (Table S3). Males initiated more agonistic behaviours and occupied a more central position within the network than females (Fig. 2b; outdegree $_{\text {males }}=13.79+8.03$, out-degree females $=6.80+4.99$, eigenvector centrality $y_{\text {males }}=0.17+0.05$, eigenvector centrality $_{\text {females }}=0.12+0.04$ ). However, receiving agonistic interactions did not vary with sex (Table S4; in-degreemales $=11.88+5.58$, in-degree females $\left._{\text {fic }}=9.87+5.94\right)$. Agonistic interactions occurred mostly between individuals of similar age (Table S3). Older birds initiated more and received fewer agonistic interactions. However, age did not influence the centrality position occupied within the network (Table S4).

\section{Affiliative interactions}

The affiliative association network deviated from random variation during autumn $\left(\mathrm{t}_{\text {observed }}=3.885\right.$, $\left.\mathrm{t}_{\text {permutation mean }}=11.937, \mathrm{p}_{\text {one-tailed }}=0.002\right)$ and winter $\left(\mathrm{t}_{\text {observed }}=3.843, \mathrm{t}_{\text {permutation mean }}=11.125\right.$, $\left.\mathrm{p}_{\text {one-tailed }}=0.002\right)$. We found effects of season, reproductive partner, age and sex on patterns of affiliative interactions. Generally, more affiliative behaviour was initiated and received during winter than autumn, independent of sex and age. Furthermore, the social centrality position of single individuals within the network did not differ between seasons (Table S2).

\section{Autumn}

A network density of $5.2 \%$ was found in the affiliative network during autumn. Affiliative interactions were mostly observed between previous and new reproductive partners. All focal animals except for two were involved in affiliative interactions. However, sex-based homophily and age-based heterophily had no influence on the selection of interaction partner (Table S3). We found no sex differences in initiating and receiving affiliative behaviour as well as no effect of sex or age on the individual centrality position within the network (Fig. 3a; out-degreemales $=11.71+13.94$, out-degree females $=17.73+16.81$, indegree $_{\text {males }}=11.88+14.97$, in-degree females $=17.47+16.23$, eigenvector centrality males $=0.03+0.14$, eigenvector centrality $_{\text {females }}=0.05+0.18$ ). Older birds increasingly initiated and received affiliative behaviours (Table S4).

\section{Winter}

Similar to autumn, the network density reached $4.7 \%$ in the affiliative network during winter, indicating relatively few connections. Affiliative interactions occurred mostly between previous and new reproductive partners. Sexbased homophily and age-based heterophily had no influence on the selection of interaction partner (Table S3). Females received significantly more affiliative interactions than males (Fig. 3b; in-degree males $=19.83+26.87$, in-degree females $=38.73+34.22$ ). However, initiating affiliative interactions did not vary with sex (out-degreemales $=24.83+29.78$, out-degree females $=30.73+30.59$ ). Sex and age had no influence on the centrality position occupied within the network (eigenvector centrality males $=0.03+0.14$, eigenvector centrality females $=0.05+0.18$ ). Older birds initiated as well as received significantly more affiliative behaviours (Table S4).

\section{Discussion}

In our study we document strong seasonal differences in patterns of proximity and social behaviour in the endangered Northern Bald Ibis. Specifically, we recorded (1) lower interindividual distance (high proximity network density) during autumn compared with winter, (2) no seasonal difference
Fig. 3 Directed social networks of the initiated and received affiliative interactions in autumn (a) and winter (b). Males are highlighted in black, females in grey. Node size increases with the age of the individuals. Edge size represents how often an individual was involved in an affiliative interaction with another colony member. Edge colour indicates the origin of the behaviour and the direction of the association is shown clockwise. $\mathrm{N}_{\text {males }}=24$, $\mathrm{N}_{\text {females }}=15$
A

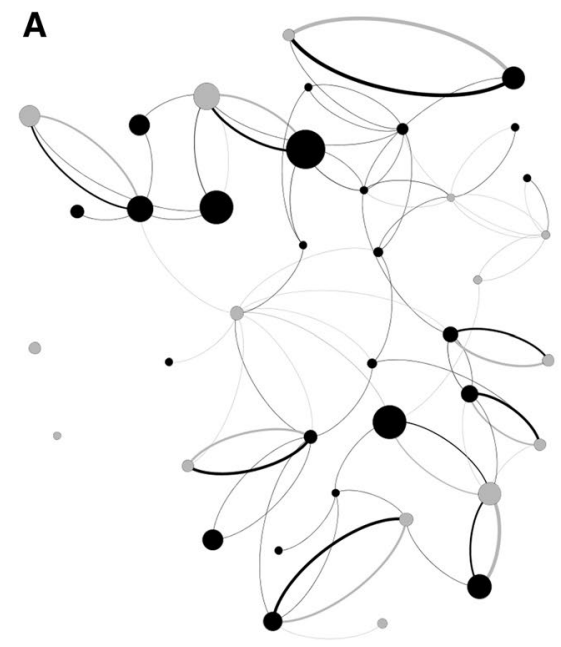

B

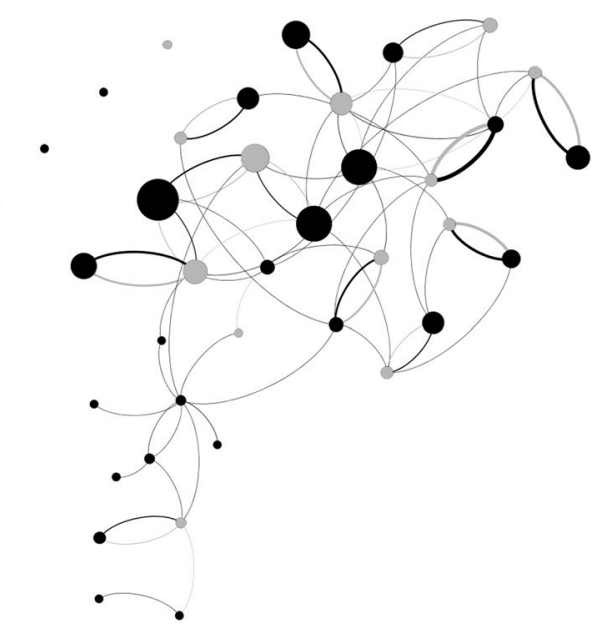


in patterns of agonistic behaviour but more agonistic interactions in males than females, (3) seasonal and sex differences in affiliative behaviour with more affiliative behaviour during winter and more affiliative behaviour received by females than males, (4) reproductive partners as preferred affiliative interaction partners, and (5) an effect of age on social and centrality position within the group, with younger birds being less central in the proximity network and receiving more agonistic interactions.

During winter, individuals associated with fewer other colony members, as shown by the number of associates, but they had stronger connections to specific individuals. Relationship patterns may have changed over time as a consequence of reproductive seasonality (Brent et al. 2013) as breeding pair formation starts anew before the onset of the forthcoming breeding season (i.e., already in autumn; Böhm and Pegoraro 2011). This was also supported by our findings that especially older individuals and reproductive partners (former or prospective mates) were observed in close proximity. Seasonal changes in affiliative interactions may also reflect differences in pair bond stability, with loose bonds during the non-breeding season and stronger bonds during the breeding season (Rowley 1985). Furthermore, season-dependent changes in associations could have important implications for conservation: For example, identifying transmission pathways of infectious diseases within an endangered species' population but also between populations (Hamede et al. 2009). Contrary to our expectations, the occurrence of agonistic encounters did not differ between seasons, whereas affiliative interactions were more evident during winter. Increased affiliative interactions may indicate a function for pair bond quality and mate familiarity. In fact, there is evidence from socially monogamous Blue-Footed Boobies (Sula nebouxii) that affiliative interactions enhance within pair coordination and cooperation during brooding and chick rearing (Sánchez-Macouzet et al. 2014).

Sex and age may strongly influence how individuals aggregate and with whom they interact (Widdig et al. 2001; Boucherie et al. 2016; Rose and Croft 2018). In the present study, patterns of agonistic and also to some extent affiliative interactions differed considerably between males and females during winter. High frequencies of initiated agonistic interactions mostly between males may reflect malemale competition for nest sites. In turn, high frequencies of received affiliative behaviours in females hint at male-male competition for mates. Previous or potentially prospective reproductive partners may invest in pair bond formation and subsequently in pair bond quality with a high exchange of affiliative behaviours. Thus, it seems that, as in other species, males and females have different behavioural patterns during winter, the onset of the breeding season, which may reflect individual investment into pair bond formation and maintenance (Röell 1978; McGraw et al. 2010; Kubitza et al. 2015).
By showing consistent levels of aggressiveness (high or low) individuals may avoid extended fights: Males, for instance, may benefit in male-male agonistic interactions through consistency in their high levels of aggressive behaviours, whereas females may benefit from low levels of agonistic behaviours (Dall et al. 2004). Our results further imply that females received affiliative behaviours predominantly from previous or potentially prospective mates.

Partner affiliation may bring significant benefits to both sexes, as socio-positive relationships can be beneficial in terms of lower levels of stress hormones, which may have a positive impact on the immune system (Puehringer-Sturmayr et al. 2018) or better access to food and protection against predators (Kalbitzer et al. 2017). This suggests that affiliative interactions among Northern Bald Ibis may also be interpreted as an investment of a partner towards containing the potentially detrimental effect of high parasite load on fitness (Frigerio et al. 2016), which was shown in Cape Ground Squirrels (Xerus inauris; Hillegass et al. 2010). In the present study, affiliative interactions frequently occurred between previous or prospective reproductive partners. However, other avian species living in year-round sociality showed different patterns: Rooks (Corvus frugilegus), for instance, do not restrict affiliative behaviour to breeding partners (Boucherie et al. 2016). Future research could test for the quality of the pair bond or for re-mating occurrence in relation to patterns of affiliative behaviour during the breeding season.

As in other species (mammals: Bekoff 1972; primates: Chalmers 1983; honey bees: Amdam 2011), our findings in Northern Bald Ibis support the idea that social interactions with conspecifics and the individual social role change with age. Stability of relationships can influence how a population reacts to environmental change. For instance, social instability may reduce survival and fitness by increasing inter-individual aggression (Linklater et al. 1999). Notably, dispersal decisions might be a consequence of early social experience (Bekoff 1977; Holekamp 1984). Up to 50\% of the juveniles in the study population disperse, some of which return during autumn (Böhm et al. in press). In our study, young Northern Bald Ibis occupied social positions at the edge of the proximity network; in addition, they received many agonistic interactions and almost no affiliative interactions. Individuals of similar age mainly engaged in agonistic interactions with each other, but there was no evidence of them being in closer proximity or being involved in affiliative interactions with conspecifics of similar age. Thus, juveniles might not have formed socio-positive relationships among themselves.

Different positions within a social network might also be associated with age-related mortality risk and potential fitness consequences. Juvenile Greylag Geese (Anser anser), for example, became more successful as breeders 
later in life than others if they had higher social connectivity during earlier life stages (Szipl et al. 2019). Because juvenile Greylag Geese form long-lasting social bonds with their parents (Rutschke 1982), this may influence reproduction early in life due to the parents' associated social position within the flock (Szipl et al. 2019); but this does not apply to Northern Bald Ibis, as offspring do not maintain long-lasting relationships with their parents (Böhm and Pegoraro 2011). As our study shows, juvenile Northern Bald Ibis occupy social positions on the edge of the network and tend to disperse instead of staying.

In addition to the parameters considered in this study (i.e., season, reproductive partner, sex and age), several additional factors could have an impact on patterns of relationships, such as density and distribution of food (Chapman 1990; Howery et al. 1998), the presence of peers (Howery et al. 1998) or behavioural phenotype (i.e., passive or active; Croft et al. 2009). Density and distribution of food, for instance, generally determines group size, as shown for instance in Spider Monkeys (Ateles geoffroyi; Chapman 1990). Even though our Northern Bald Ibis population receives supplemental feeding during winter, behavioural observations were not performed in this context; therefore, we tend to exclude such an effect on inter-individual distance (i.e., proximity) or agonistic encounters in the present study. Furthermore, social factors (i.e., peers) can alter location and habitat use by increasing distance or associations to specific individuals (e.g., yearling cattle, Howery et al. 1998). Our results suggest that mainly pair partners (former/prospective mates) are involved in establishing social ties. This suggests that colony formation in the Northern Bald Ibis serves mainly predator avoidance and info-parasitism, but is not the basis for cooperation that goes beyond the reproductive pair, whereas Greylag Geese establish female-bonded clans within the flock in addition to the reproductive pair (Frigerio et al. 2001). Behavioural traits may also modify an individual's number of ties, as passive individuals may seek refuge in a social group (e.g., Guppies (Poecilia reticulata), Croft et al. 2009). Regarding the role of individual behavioural phenotype, our unpublished data suggest that passive juveniles are more likely to be in the centre of a social group compared to active juveniles (PuehringerSturmayr et al. in prep). We are aware that the aviary conditions might have affected the patterns we observed. Most birds remained at their nest site during winter, probably because of the harsh alpine weather conditions, while the birds freely roamed the foraging grounds throughout the valley during autumn. Aviary size could have led to a concentration of interactions and proximity between colony members in winter. However, as the birds were able to leave the aviary at any point, and we indeed made observations outside the aviary as well, we conclude that the observed patterns of relationships were not fully constrained by the location.

Investigating patterns of relationships in an endangered species is relevant for conservation and reintroduction projects in the wild. The social complexity of a Northern Bald Ibis colony is a challenge when reintroducing individuals (Bowden et al. 2010) as the social structure of a released group may have tremendous effects on reproductive success (Böhm and Pegoraro 2011). Our results imply that young Northern Bald Ibis may be less optimal for reintroduction because of greater mortality and dispersal risk associated with their social position within the network than adults. However, in combination with 'human parents' for the chicks, the release of groups of hand-reared Northern Bald Ibis chicks with contact to human parents has been shown to be effective (Jordan et al. 2003). From other study systems, there is evidence that the age structure of a released group has an immense effect on survival and fertility (Sarrazin and Barbault 1996); therefore, designing release programs that take into account age-specific bottlenecks to survival and the strengths and limitations of hand rearing should inform approaches. Specifically, understanding the social position of individuals could help to select specific individuals for reintroduction and to predict seasonal trends in habitat use associated with behaviour (Snijders et al. 2017), age-related mortality risk associated with different positions within the social network (Ellis et al. 2017), and not least the role of male affiliative behaviour for pair bond formation (Kubitza et al. 2015).

Acknowledgements This study was funded by the project Sparkling Science SPA-05/026 and by TCS-02/06. We gratefully acknowledge Matthias-Claudio Loretto for assistance with the statistics, and Lukas Schiefermair for some logistics. We are grateful to the Cumberland Game Park Grünau im Almtal for the excellent cooperation. We acknowledge the permanent support by the Herzog von Cumberland Stiftung and the Verein der Förderer der Konrad Lorenz Forschungsstelle. Open access funding provided by University of Vienna.

Author contributions DF, VP-S, KK and TS contributed to the study conception and design. Data collection was performed by TS. Data analysis was done by VP-S and TS. The first draft of the manuscript was written by VP-S, TS and DF. SK and KK revised the manuscript, contributed analysis tools, and reviewed drafts of the paper. All authors commented on previous versions of the manuscript and read and approved the final manuscript.

Funding Open access funding provided by University of Vienna.

\section{Compliance with ethical standards}

Conflict of interest The authors declare that they have no conflict of interest.

Ethics This study was carried out following all current Austrian laws and regulations regarding the work with wildlife. Observing the 
animals was performed under Animal Experiment Licence Number 66.006/0026-WF/V/3b/2014 by the Austrian Federal Ministry for Science and Research (EU Standard, equivalent to the Animal Ethics Board).

Open Access This article is licensed under a Creative Commons Attribution 4.0 International License, which permits use, sharing, adaptation, distribution and reproduction in any medium or format, as long as you give appropriate credit to the original author(s) and the source, provide a link to the Creative Commons licence, and indicate if changes were made. The images or other third party material in this article are included in the article's Creative Commons licence, unless indicated otherwise in a credit line to the material. If material is not included in the article's Creative Commons licence and your intended use is not permitted by statutory regulation or exceeds the permitted use, you will need to obtain permission directly from the copyright holder. To view a copy of this licence, visit http://creativecommons.org/licenses/by/4.0/.

\section{References}

Altmann J (1974) Observational study of behavior: sampling methods. Behaviour 49:227-267

Amdam GV (2011) Social context, stress, and plasticity of aging. Aging Cell 10:18-27. https://doi.org/10.1111/j.1474-9726.2010.00647.x

Archie EA, Tung J, Clark M et al (2014) Social affiliation matters: both same-sex and opposite-sex relationships predict survival in wild female baboons. Proc R Soc B Biol Sci 281:20141261

Bastian M, Heymann S, Jacomy M (2009) Gephi: an open source software for exploring and manipulating networks. Int. AAAI Conf. Weblogs Soc. Media

Bekoff M (1972) The development of social interaction, play, and metacommunication in mammals: an ethological perspective. Q Rev Biol 47:412-434

Bekoff M (1977) Mammalian dispersal and the ontogeny of individual behavioral phenotypes. Am Nat 111:715-732

Bengston SE, Jandt JM (2014) The development of collective personality: the ontogenetic drivers of behavioral variation across groups. Front Ecol Evol 2:1-13. https://doi.org/10.3389/fevo.2014.00081

BirdLife International (2020) Species factsheet: Geronticus eremita. http://www.birdlife.org. Accessed 10 Jan 2020

Blonder B, Wey TW, Dornhaus A et al (2012) Temporal dynamics and network analysis. Methods Ecol Evol 3:958-972. https://doi. org/10.1111/j.2041-210X.2012.00236.x

Blumstein DT, Wey TW, Tang K (2009) A test of the social cohesion hypothesis: interactive female marmots remain at home. Proc $\mathrm{R}$ Soc B 276:3007-3012. https://doi.org/10.1098/rspb.2009.0703

Bogatti SP, Everett MG, Freeman LC (2002) Ucinet 6 for windows: software for social network analysis. Analytic Technologies, Harvard, MA

Böhm C (1999) Ten years of northern bald ibis EEP: a review. In: Boehm C (ed) 2nd international EEP studbook. Alpenzoo, Innsbruck, pp 73-88

Böhm C, Pegoraro K (2011) Der Waldrapp. Westarp WissenschaftenVerlagsgesellschaft mbH, Hohenwarsleben

Borgeaud C, Sosa S, Bshary R et al (2016) Intergroup variation of social relationships in wild vervet monkeys: a dynamic network approach. Front Psychol 7:915. https://doi.org/10.3389/fpsyg .2016 .00915

Boucherie PH, Mariette MM, Bret C, Dufour V (2016) Bonding beyond the pair in a monogamous bird: Impact on social structure in adult rooks (Corvus frugilegus). Behaviour 153:897-925. https://doi. org/10.1163/1568539X-00003372
Bowden CGR, Böhm C, Jordan MJR, Smith KW (2010) Why is reintroduction of Northern Bald Ibis Geronticus eremita so complicated? An overview of recent progress and potential. In: Lamont MM (ed) The proceedings of the IV international symposium on breeding birds in captivitiy; 2007 Sept 12-Sept 16; Toronto. pp $27-35$

Brent LJN, MacLarnon A, Platt ML, Semple S (2013) Seasonal changes in the structure of rhesus macaque social networks. Behav Ecol Sociobiol 67:349-359. https://doi.org/10.1007/s00265-0121455-8.Seasonal

Cameron EZ, Setsaas TH, Linklater WL (2009) Social bonds between unrelated females increase reproductive success in feral horses. PNAS 106:13850-13853

Chalmers N (1983) The development of social relationships. In: Halliday TR, Slater PJB (eds) Genes, development and learning. W. H, Freeman, New York, pp 114-148

Chapman CA (1990) Association patterns of spider monkeys: the influence of ecology and sex on social organization. Behav Ecol Sociobiol 26:409-414

Crofoot MC, Rubenstein DI, Maiya AS, Berger-Wolf TY (2011) Aggression, grooming and group-level cooperation in whitefaced capuchins (Cebus capucinus): insights from social networks. Am J Primatol 73:1-13. https://doi.org/10.1002/ ajp.20959

Croft DP, Krause J, Darden SK et al (2009) Behavioural trait assortment in a social network: patterns and implications. Behav Ecol Sociobiol 63:1495-1503

Dall SRX, Houston AI, McNamara JM (2004) The behavioural ecology of personality: consistent individual differences from an adaptive perspective. Ecol Lett 7:734-739. https://doi.org/10.11 11/j.1461-0248.2004.00618.x

Dall SRX, Giraldeau L-A, Olsson O et al (2005) Information and its use by animals in evolutionary ecology. Trends Ecol Evol 20:187193. https://doi.org/10.1016/j.tree.2005.01.010

Davies NB, Krebs JR, West SA (2012) An introduction to behavioural ecology, 4th edn. Wiley-Blackwell, Oxford

Dekker D, Krackhardt D, Snijders TAB (2007) Sensitivity of MRQAP tests to collinearity and autocorrelation conditions. Psychometrika $72: 563-581$

del Hoyo J, Elliott A, Sargatel J (1992) Handbook of the birds of the world, vol 1: Ostrich to Ducks. Lynx Editions, Barcelona

Dunbar R, Shultz S (2010) Bondedness and sociality. Behaviour 147:775-803. https://doi.org/10.1163/000579510X501151

Ellis S, Franks DW, Nattrass S et al (2017) Mortality risk and social network position in resident killer whales: sex differences and the importance of resource abundance. Proc R Soc B Biol Sci 284:20171313

Estrada A, Garber PA, Rylands AB et al (2017) Impending extinction crisis of the world's primates: why primates matter. Sci Adv 3:e1600946

Farine DR, Whitehead H (2015) Constructing, conducting and interpreting animal social network analysis. J Anim Ecol 84:11441163. https://doi.org/10.1111/1365-2656.12418

Formica VA, Wood CW, Larsen WB et al (2012) Fitness consequences of social network position in a wild population of forked fungus beetles (Bolitotherus cornutus). J Evol Biol 25:130-137. https:// doi.org/10.1111/j.1420-9101.2011.02411.x

Frigerio D, Weiss B, Kotrschal K (2001) Spatial proximity among adult siblings in greylag geese (Anser anser): evidence for female bonding? Acta Ethol 3:121-125

Frigerio D, Cibulski L, Ludwig SC et al (2016) Excretion patterns of coccidian oocysts and nematode eggs during the reproductive season in Northern Bald Ibis (Geronticus eremita). J Ornithol 77:955-961. https://doi.org/10.1007/s10336-015-1317-z

Hamede RK, Bashford J, McCallum H, Jones M (2009) Contact networks in a wild Tasmanian devil (Sarcophilus harrisii) population: 
using social network analysis to reveal seasonal variability in social behaviour and its implications for transmission of devil facial tumour disease. Ecol Lett 12:1147-1157. https://doi.org/1 0.1111/j.1461-0248.2009.01370.x

Hanneman RA, Riddle M (2005) Introduction to social network methods. Analytictech.com, Riverside CA

Hillegass MA, Waterman JM, Roth JD (2010) Parasite removal increases reproductive success in a social African ground squirrel. Behav Ecol 21:696-700. https://doi.org/10.1093/beheco/arq041

Hirsch BT, Maldonado JE (2011) Familiarity breeds progeny: sociality increases reproductive success in adult male ring-tailed coatis (Nasua nasua). Mol Ecol 20:409-419. https://doi.org/10.1111/ j.1365-294X.2010.04940.x

Hirsch BT, Stanton MA, Maldonado JE (2012) Kinship Shapes affiliative social networks but not aggression in ring-tailed coatis. PLoS ONE 7:e37301. https://doi.org/10.1371/journal.pone.0037301

Holekamp KE (1984) Dispersal in ground-dwelling sciurids. In: Murie JO, Michener GR (eds) The biology of ground-dwelling squirrels. University of Nebraska Press, Lincoln, pp 297-320

Howery L, rr D, Provenza FD, Banner RE, Scott CB (1998) Social and environmental factors influence cattle distribution on rangeland. Appl Anim Behav Sci 55:231-244

Idani G (1991) Social relationships between immigrant and resident bonobo (Pan paniscus) females at wamba. Folia Primatol 57:83-95

Illany A, Booms AS, Holekamp KE (2015) Topological effects of network structure on long-term social network dynamics in a wild mammal. Ecol Lett 18:687-695. https://doi.org/10.1111/ele.12447 .Topological

Jacoby DMP, Croft DP, Sims DW (2011) Social behaviour in sharks and rays: analysis, patterns and implications for conservation. Fish Fish. https://doi.org/10.1111/j.1467-2979.2011.00436.x

Jordan M, Boehm C, Bowden C (2003) Group Workshop on guidelines for Northern bald Ibis release. In: Boehm C, Bowden CGR, Jordan MJR (eds) Northern Bald Ibis Conservation and Reintroduction Workshop. Proceedings of the international advisory group for the northern bald ibis (IAGNBI) meeting Alpenzoo Innsbruck, July 2003

Kalbitzer U, Bergstrom ML, Carnegie SD et al (2017) Female sociality and sexual conflict shape offspring survival in a Neotropical primate. PNAS 114:1892-1897. https://doi.org/10.1073/pnas.16086 25114

Krause J, Ruxton GD (2002) Living in groups. Oxford University Press, Oxford

Kubitza RJ, Bugnyar T, Schwab C (2015) Pair bond characteristics and maintenance in free-flying jackdaws Corvus monedula: effects of social context and season. J Avian Biol 46:206-215. https://doi. org/10.1111/jav.00508.Pair

Kulahci IG, Rubenstein DI, Bugnyar T et al (2016) Social networks predict selective observation and information spread in ravens. $\mathrm{R}$ Soc Open Sci 3:160256

Kurvers RHJM, Krause J, Croft DP et al (2014) The evolutionary and ecological consequences of animal social networks : emerging issues. Trends Ecol Evol 29:326-335. https://doi.org/10.1016/j. tree.2014.04.002

Lehmann J, Korstjens AH, Dunbar RIM (2007) Group size, grooming and social cohesion in primates. Anim Behav 74:1617-1629

Lindsell JA, Serra G, Peske L et al (2009) Satellite tracking reveals the migration route and wintering area of the middle east population of critically endangered northern bald ibis Geronticus eremita. Oryx 43:329-335. https://doi.org/10.1017/S0030605309001963

Linklater WL, Cameron EZ, Minot EO, Stafford KJ (1999) Stallion harassment and the mating system of horses. Anim Behav 58:295-306
McDonald M, Johnson S (2014) 'There's an app for that': a new program for the collection of behavioural field data. Anim Behav 95:81-87. https://doi.org/10.1016/j.anbehav.2014.06.009

McGraw L, Székely T, Young LJ (2010) Pair bonds and parental behaviour. In: Székely T, Moore AJ, Komdeur J (eds) Social behaviour: genes, ecology and evolution. Cambridge University Press, Cambridge, pp 271-301

Palagi E, Cordoni G (2009) Postconflict third-party affiliation in Canis lupus: do wolves share similarities with the great apes? Anim Behav 78:979-986. https://doi.org/10.1016/j.anbehav.2009.07.017

Pegoraro K (1992) Zur Ethologie des Waldrapps (Geronticus eremita L.). Beobachtungen in Volieren und im Freiland (Türkei, Marokko). Dissertation Univ, Innsbruck

Pinter-Wollman N, Isbell LA, Hart LA (2009) The relationship between social behaviour and habitat familiarity in African elephants (Loxodonta africana). Proc R Soc London B Biol Sci 276:1009-1014. https://doi.org/10.1098/rspb.2008.1538

Puehringer-Sturmayr V, Wascher CAF, Loretto M-C et al (2018) Seasonal differences of corticosterone metabolite concentrations and parasite burden in northern bald ibis (Geronticus eremita): the role of affiliative interactions. PLoS ONE 13:e0191441. https://doi.org/10.1371/journal.pone.0191441

R Core Team (2019) R: a language and environment for statistical computing. R Foundation for Statistical Computing, Vienna, Austria

R Core Team (2020) R: a language and environment for statistical computing. R Foundation for Statistical Computing, Vienna, Austria

Röell A (1978) Social behaviour of the jackdaw, Corvus monedula, in relation to its niche. Behaviour 64:1-124

Romey WL, Wallace AC (2007) Sex and the selfish herd: sexual segregation within nonmating whirligig groups. Behav Ecol 18:910 915. https://doi.org/10.1093/beheco/arm057

Rose PE, Croft DP (2018) Quantifying the social structure of a large captive flock of greater flamingos (Phoenicopterus roseus): potential implications for management in captivity. Behav Processes 150:66-74

Rowley I (1985) Re-mating in birds. In: Bateson P (ed) Mate choice. Cambridge University Press, Cambridge, pp 331-360

Rutschke E (1982) Stability and dynamics in the social structure of the Greylag goose (Anser anser). Aquila 89:39-55

Sánchez-Macouzet O, Rodríguez C, Drummond H (2014) Better stay together: pair bond duration increases individual fitness independent of age-related variation. Proc R Soc B Biol Sci 281:20132843

Sarrazin F, Barbault R (1996) Reintroduction: challenges and lessons for basic ecology. Trends Ecol Evol 11:474-478

Silk JB (2007) Social components of fitness in primate groups. Science 80-(317):1347-1351. https://doi.org/10.1126/science.1140734

Silk JB, Altmann J, Alberts SC (2006) Social relationships among adult female baboons (Papio cynocephalus) I. Variation in the strength of social bonds. Behav Ecol Sociobiol 61:183-195. https://doi. org/10.1007/s00265-006-0249-2

Snijders L, Blumstein DT, Stanley CR, Franks DW (2017) Animal social network theory can help wildlife conservation. Trends Ecol Evol 32:567-577. https://doi.org/10.1016/j.tree.2017.05.005

Sorato E, Kotrschal K (2006) Hormonal and behavioural symmetries between the sexes in the northern bald ibis. Gen Comp Endocrinol 146:265-274. https://doi.org/10.1016/j.ygcen.2005.11.020

Sosa S, Puga-Gonzalez I, Hu F et al (2020) A multilevel statistical toolkit to study animal social networks: the animal network toolkit software (ANTs) R package. Sci Rep 10:12507. https:// doi.org/10.1038/s41598-020-69265-8

Stanton MA, Mann J (2012) Early social networks predict survival in wild bottlenose dolphins. PLoS ONE 7:e47508. https://doi. org/10.1371/journal.pone.0047508

Strandburg-Peshkin A, Farine DR, Crofoot MC, Couzin ID (2017) Habitat and social factors shape individual decisions and 
emergent group structure during baboon collective movement. Elife 6:e19595. https://doi.org/10.7554/eLife.19505

Szipl G, Depenau M, Kotrschal K et al (2019) Costs and benefits of social connectivity in juvenile Greylag geese. Sci Rep 9:12839. https://doi.org/10.1038/s41598-019-49293-9

Tuckova K, Zisser B, Kotrschal K (1998) Versuch der Ansiedlung einer ortsfesten Waldrapp-Kolonie an der Konrad-Lorenz-Forschungsstelle. ÖKOL 20:3-14

Verdolin JL (2006) Meta-analysis of foraging and predation risk tradeoffs in terrestrial systems. Behav Ecol Sociobiol 60:457-464. https://doi.org/10.1007/s00265-006-0172-6

Wey TW, Blumstein DT (2010) Social cohesion in yellow-bellied marmots is established through age and kin structuring. Anim Behav 79:1343-1352. https://doi.org/10.1016/j.anbehav.2010.03.008

Wey T, Blumstein DT, Shen W, Jordán F (2008) Social network analysis of animal behaviour: a promising tool for the study of sociality. Anim Behav 75:333-344. https://doi.org/10.1016/j. anbehav.2007.06.020

Wickler W, Seibt U (1985) Monogamy: an ambiguous concept. In: Bateson P (ed) Mate Choice. Cambridge University Press, Cambridge, pp 33-50

Widdig A, Nürnberg P, Krawczak M et al (2001) Paternal relatedness and age proximity regulate social relationships among adult female rhesus macaques. PNAS 98:13769-13773. https://doi. org/10.1073/pnas.241210198

Publisher's Note Springer Nature remains neutral with regard to jurisdictional claims in published maps and institutional affiliations. 